\title{
Design, Modelling\& Simulation of Double Sided Linear Segmented Switched Reluctance Motor
}

\author{
Dr. K. Ravi Chandrudu ${ }^{1}$,T. Naga Jyothi ${ }^{2}$ P. YohanBabu ${ }^{3}$, \\ G. V. P Anjaneyulu ${ }^{4}$ \\ ${ }^{1,2,3}$ EEE Department, $K E C W$, Narasaraopeta, A.P. India \\ ${ }^{4}$ Research Scholar, $S$ V University College of Engg, S V UNIVERSITY, A.P. India
}

\begin{abstract}
This paper presents the modelling, simulation, and speed control aspects of a 3-phase 6/4 linear switched reluctance motor (LSRM) drives. The Linear switched reluctance motor (LSRM) has never been a popular choice for direct-drive linear motion control system; because it is difficult to control and its output has high torque ripples. It is also due to the fact that the actuator's characteristic is highly dependent on its complex magnetic circuit, which is difficult to model, simulate, and control.Fourier series expression of phase selfinductance under the assumption of negligible mutual effect and various losses is introduced to describe the nonlinear dynamic model of SRM.Simulation results have shown the rationality of model and validity of control strategy. By virtue of MATLAB/SIMULINK, the models of various subsystems are achieved and the modelling procedure is described in detail. Linear segmented switched reluctance motor (LSSRM) using full pitched winding can give 40 - 80\% higher torque than conventional SRM for the same frame size. This increase in torque is due to the increase in aligned inductance. However, full pitch winding results in high copper loss, and high active weight. Hence, in this paper, single tooth or concentric winding to replace the full pitch winding of LSSRM is proposed. In order to obtain the same flux paths as with full pitch winding, all the three phases must be excited simultaneously. The torque is produced due to changes in mutual inductance. This method of winding results in reduction of copper, and therefore, weight. With such an arrangement, one phase only requires DC supply.
\end{abstract}

Keywords:LinearMotion, LinearSwitchedReluctance Motor,Stator, Rotor, chopping control.

\section{Introduction}

The use of switched reluctance machines (SRM) in variable speed applications is increasing because of the rugged construction and simple converter power circuit configuration. However, this machine has limitations such as low torque to weight ratio, acoustic noise, vibration and torque ripple. Some of these limitations namely low power density, acoustic noise are mitigated in segmented switched reluctance machine (SSRM) which has full pitched winding. It is shown there that SSRM can give $40-80 \%$ higher torque than SRM for the same frame size. This increase in torque is because of the increase in aligned flux, while the torque of SSRM increases with the use of full pitch winding, the end winding volume of the motor also increases by a factor which depends on the ratio of motor air gap diameter (D) to stack length (L). For higher values of $D / L$ ratio, as required in in-wheel electric vehicle (EV) or in fans, the copper loss and end winding volume become significantly higher than those corresponding to concentric winding. This arrangement is particularly more effective for machines with $\mathrm{D} / \mathrm{L}$ ratio equal to and greater than 2.[4] LSSRM with concentric winding arrangement is henceforth referred to as SSRM. The difference is that the windings, instead of being full pitched, are concentric. Three concentric windings when excited together have the same effect as one full pitch winding.

\section{Design Of Srm, Ssrm, Lsrm}

In order to compare CSSSRM with SSRM, a $6 \mathrm{~kW}, 2000 \mathrm{rpm}$ machine as in [3] is designed and the machine dimensions are given in Table I. A 6/4 rotary SRM (SSRM) is designed for a power capacity identical to that of the LSSRM. The material used for the laminations is M19 steel, which is made of non oriented silicon steel. The rotary SRM has a stator pole angle and a rotor pole angle. The speed of the rotary SSRM $N$ in rpm. $D$ is the bore diameter of the rotary SSRM. The power output equation of a rotary SSRM is

$\mathrm{P}=\mathrm{k}_{\mathrm{e}} \mathrm{k}_{\mathrm{d}} \mathrm{k}_{1} \mathrm{k}_{2} \mathrm{BA}_{\mathrm{s}} \mathrm{D}^{2} \mathrm{LN}_{\mathrm{r}}$ 


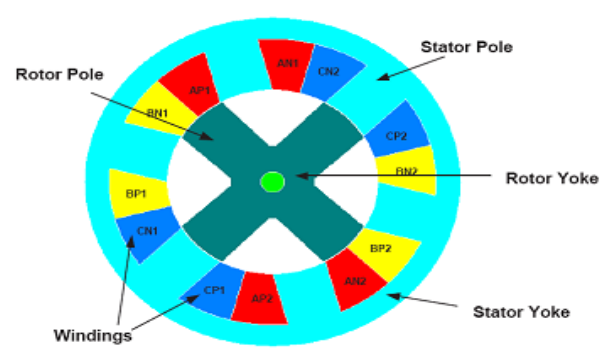

Fig.1: VSRM

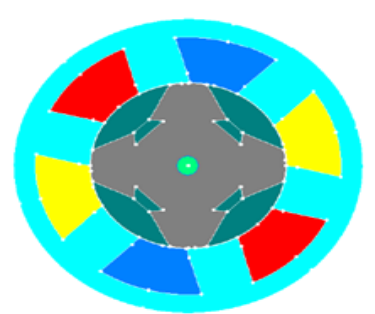

Fig.2: SSRM

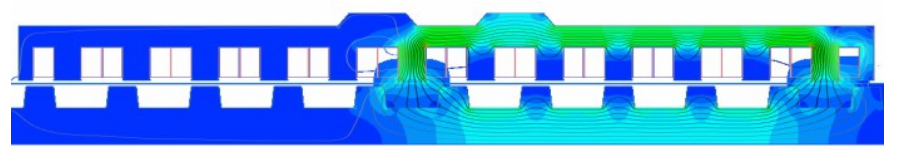

Fig.3: LSSRM

Where $\mathrm{P}$ is the power output, $\mathrm{k}_{\mathrm{e}}$ is the efficiency, $\mathrm{k}_{\mathrm{d}} \mathrm{is}$ the duty cycle determined by the current conduction angle for each rising inductance profile, $\mathrm{k}_{1}=\prod^{2} / 120, \mathrm{k}_{2}$ is a variable dependent on the operating point and is determined by using aligned saturated inductance and unaligned inductance, $\mathrm{B}$ is the stator pole flux density at the aligned position, $\mathrm{A}_{\mathrm{s}}$ is the specific electric loading which is defined as ampere conductor per meter of stator inner periphery, $\mathrm{L}$ is the stack length of the magnetic core.

The bore diameter is obtained from the power output equation as

$$
D=\sqrt{\frac{P \pi}{60 \cdot k_{e} k_{d} k_{1} k_{2} k B A_{s} v_{m}}}
$$

For a power rating of $6 \mathrm{kw}, 2000 \mathrm{rpm}$

$\begin{array}{lll}\text { Stack length } & = & 114 \mathrm{~mm} \\ \text { Din } & = & 80.648 \mathrm{~mm}\end{array}$

From the above data we can calculate

Do/Din $\quad=\quad 2$

Do $\quad=\quad 199.98 \mathrm{~mm}$

\section{Normal SRM}

\section{Stator side design}

Stator Pole Arc $\quad \beta,=\frac{2 \pi}{p_{s} \times p_{r} / 2}$

Stator Pole Width $S_{p s}=\frac{D_{h}}{2} \beta_{s} \times \frac{\pi}{180}$

$$
\text { Stator Yoke Width } \quad S_{y w}=\frac{A_{s y}}{L}
$$

Stator Pole Height $\quad h_{s}=\frac{D_{o}}{2}-\frac{D_{b n}}{2}-S_{y w}$ 


\section{+2. Rotor Side Design}

$$
\begin{array}{r}
\text { Rotor Pole Arc } \beta_{r}>\beta_{s} \\
\text { Rotor Pole Width } R_{p w r}=\left(\frac{D_{m}}{2}-g\right) \beta_{r} \times \frac{\pi}{180} \\
\text { Rotor yoke width } \quad R_{y w}=\frac{A_{p y}}{L} \\
\text { Rotor Pole Height } h_{r}=\frac{D_{t n}}{2}-g-\frac{D_{s h}}{2}-R_{y n}
\end{array}
$$

From the Magnetic Circuit of Normal SRM

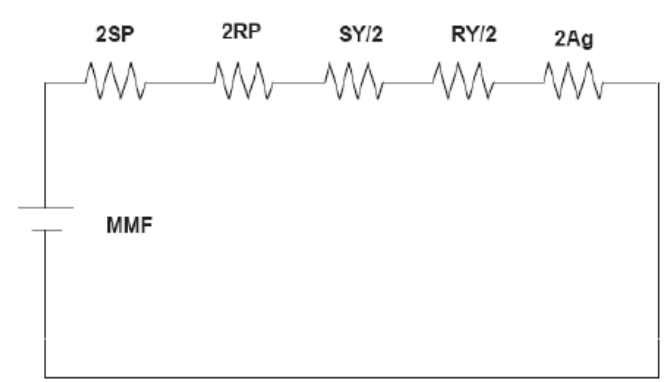

Fig. 4:Magnetic circuit for SRM

$$
\text { Totalreluc } \tan c e=2 R P+2 S P+2 A g+\frac{R Y}{2}+\frac{S Y}{2}
$$

\section{Segmented SRM (SSRM)}

\section{Stator side design}

$$
\begin{array}{r}
\text { Stator Pole Arc } \quad \beta_{s}=\frac{2 \pi}{p_{s} \times p_{r} / 2} \\
\text { Stator Pole Width } \quad S_{p w}=\frac{D_{b w}}{2} \beta_{s a c r m a l} \times \frac{\pi}{180} \\
\text { Stator Yoke Width } \quad S_{s w}=\frac{A_{s v}}{L} \\
\text { Stator Pole Height } h_{s}=\frac{D_{o}}{2}-\frac{D_{n w}}{2}-S_{y w}-\text { poleshoeheight }
\end{array}
$$

\section{Rotor side design}

$$
\text { Rotor Pole Arc } \beta_{\text {ractul }}=2 \times \beta_{\text {sactul }}
$$

$$
\begin{aligned}
& \text { Rotor Pole Width } R_{p w r}=\left(\frac{D_{p w}}{2}-g\right) \beta_{r} \times \frac{\pi}{180} \\
& \text { Rotor Pole Height } \quad h_{r}=\frac{D_{b n}}{2}-g-\frac{D_{s h}}{2}-R_{y w}
\end{aligned}
$$

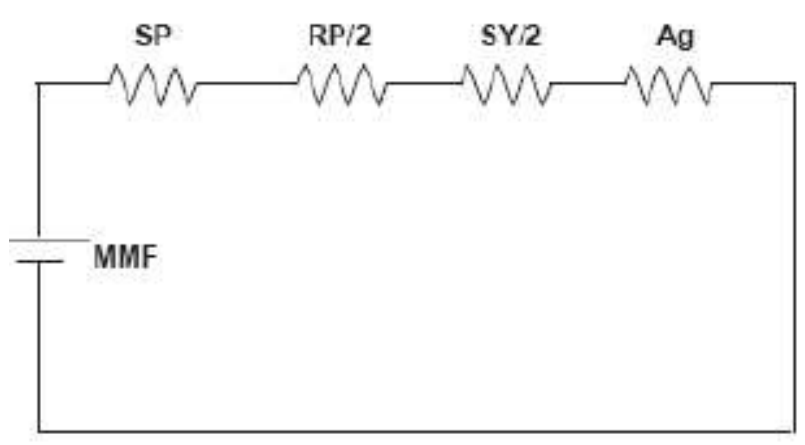

Fig. 5:Magnetic circuit for SSRM 
Size of the Conductor $J=\frac{I_{p}}{\sqrt{4} a}$

Table 1:Design Data Of Vrsm, Ssrm

\begin{tabular}{|c|c|c|}
\hline & VSRM & SSRM \\
\hline OUTER DIAMETER & $80.648 \mathrm{~mm}$ & $80.648 \mathrm{~mm}$ \\
\hline INNER DIAMETER & $161.296 \mathrm{~mm}$ & $161.296 \mathrm{~mm}$ \\
\hline STACK LENGTH & $114 \mathrm{~mm}$ & $114 \mathrm{~mm}$ \\
\hline STATOR POLE ARC & 30 & 40 \\
\hline STATOR POLE WIDTH & $28.150 \mathrm{~mm}$ & $28.150 \mathrm{~mm}$ \\
\hline STATOR YOKE WIDTH & $21.1096 \mathrm{~mm}$ & $28.150 \mathrm{~mm}$ \\
\hline STATOR POLE HEIGHT & $29.769 \mathrm{~mm}$ & $7.173 \mathrm{~mm}$ \\
\hline ROTOR POLE ARC & 32 & 80 \\
\hline ROTOR POLE WIDTH & $20.95 \mathrm{~mm}$ & $55.88 \mathrm{~mm}$ \\
\hline ROTOR YOKE WIDTH & $6.59 \mathrm{~mm}$ & ------ \\
\hline ROTOR POLE HEIGHT & $19.4273 \mathrm{~mm}$ & $19.4273 \mathrm{~mm}$ \\
\hline RELUCTANCE & 241606.76 & 82495.72 \\
\hline SHAFT DIAMETER & $28 \mathrm{~mm}$ & $28 \mathrm{~mm}$ \\
\hline RATED CURRENT & $15 \mathrm{~A}$ & $15 \mathrm{~A}$ \\
\hline
\end{tabular}

III. Main Simulink Model

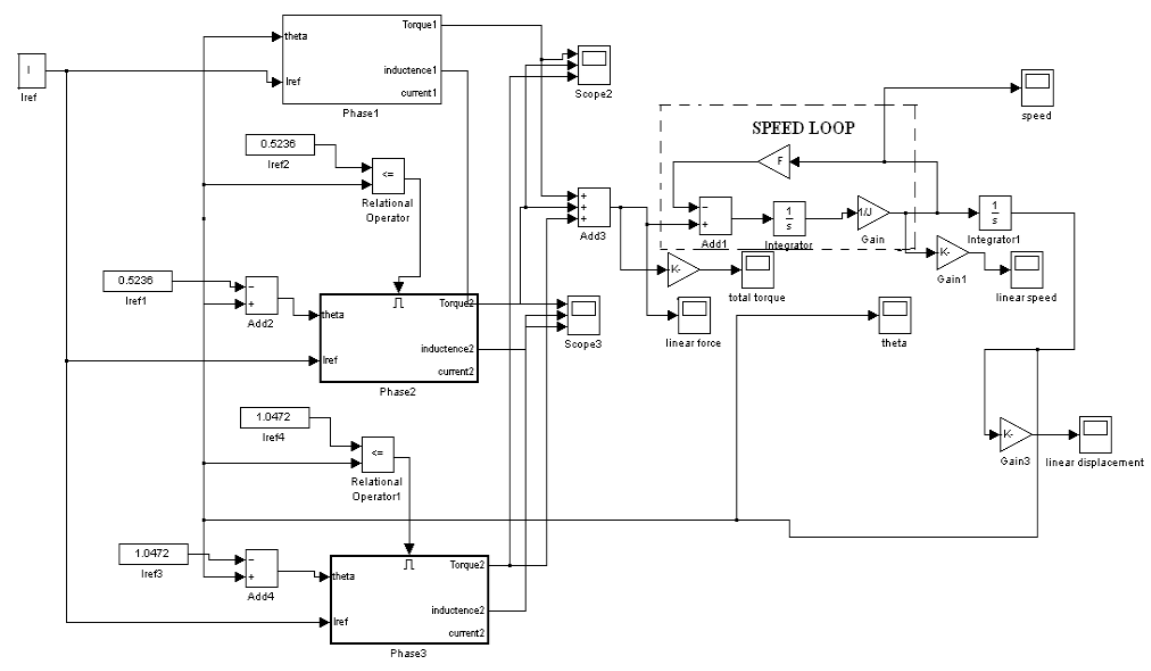

Fig. 6.Simulink Model for 6/4 LSSRM

IV. SIMULATION RESULTS

The Simulation results for current per phase, Inductance characteristics, Torque characteristics, linear speed of LSRM, Speed of LSSRM, are shown in Fig 7, Fig 8, Fig 9, Fig10, Fig11 as follows. 


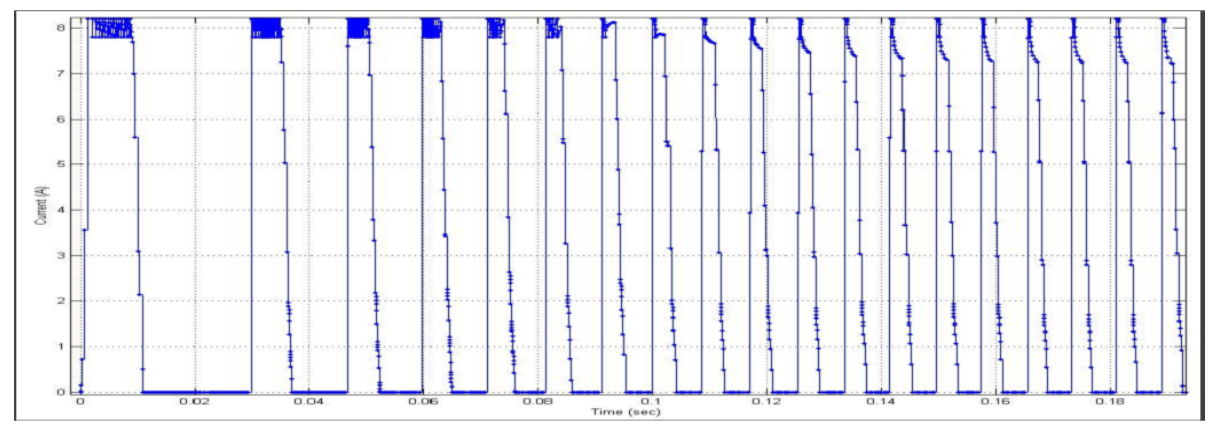

Fig. 7: Current per phase

The below figure shows the Inductance waveforms in three phases $a, b, c$ respectively

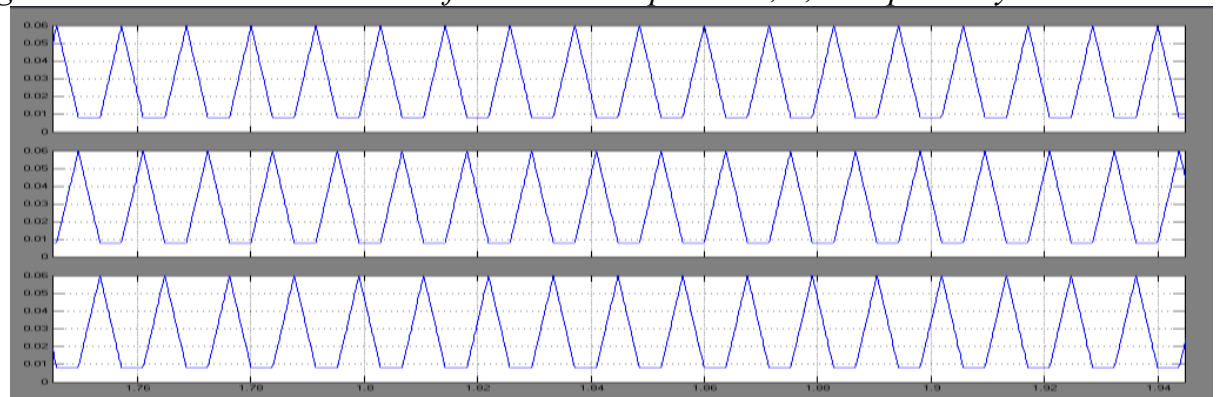

Fig. 8: Inductance characteristics

The below figure shows the Torque waveforms in three phases $a, b, c$ respectively.

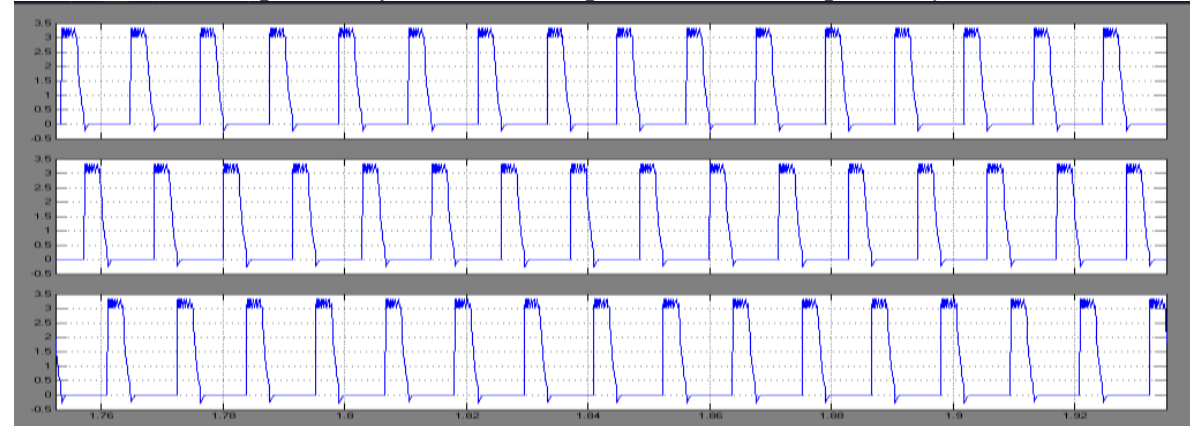

Fig. 9: Torque characteristics

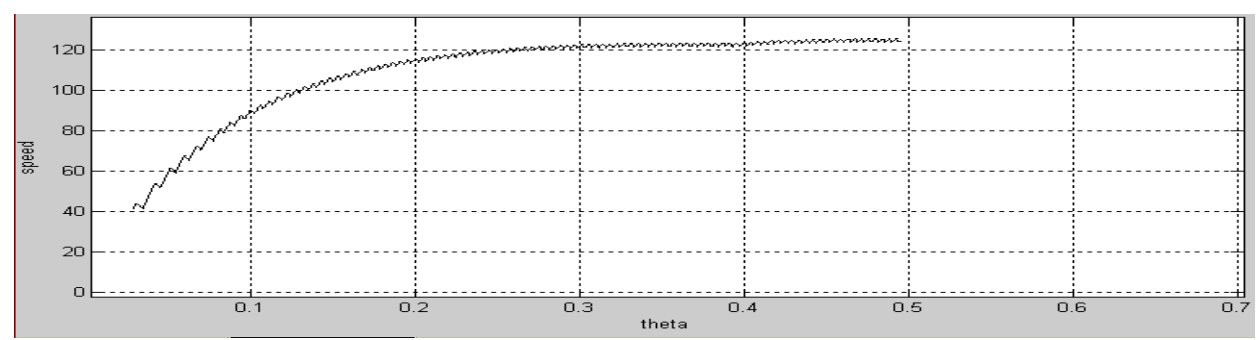

Fig. 10.Linear Speed of LSRM

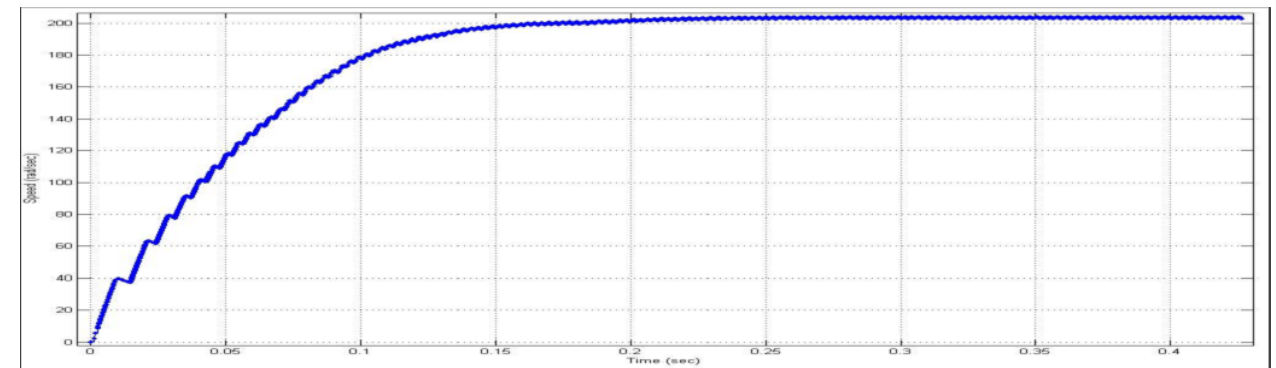

Fig. 11: Speed of LSSRM 


\section{Conclusion}

A high torque and low weight Linear segmented switched reluctance (LSSRM) machine is proposed. Design for normal SRM, Segmented SRM, Linear SSRM and comparing the results.Non-linear dynamic model for simulating adjustable speed performance of a LSSRM drive has been described in detail.The model is a general one with simple representation in MATLAB functions. Good results can be achieved if the current shape, amplitude, advance angle and the pulse duration are controlled; the cost of manufacturing is less, as concentric coils are easier to wind than full pitched coils. The structure is mechanically robust as rotor segments are embedded in aluminium core. Factors affecting the average torque are identified.

\section{References}

[1]. T. J. E Miller: "Switched reluctance motors and their control", Magna Physics Publications/Oxford university press (1993).

[2]. R. Krishnan,"Switched Reluctance Motor Drives”, Industrial Electronics Series, CRC Press (2001).

[3]. J. Oyama, T. Higuchi, T. Abe and N. Kifuji, "Novel Switched reluctance motor with segmented core embedded in Aluminium rotor block," Papers of technical meeting on rotating machinery, IEEJ Trans, Vol.126, No.4, 2006.

[4]. Mr.Myo Min, 'Design and Calculation of 75W Three-phase Linear Switched Reluctance Motor”, The Department of Electrical Power Engineering, Mandalay Technological University, Myanmar

[5]. NareshVattikuti, Vandana R and B. G. Fernandes "A high power density Outer rotor segmented switched reluctance motor" Indian Patent Application No 197/MUM/2009.

[6] NareshVattikuti, VandanaRallabandi and B. G. Fernandes, “A Novel High Torque, Low Weight Segmented Switched Reluctance Motor", IEEE Power Electronics Specialist conference Issue 15-19, Pag. 1223-1228, Jun.82008, Rhodes, Greece. 